\title{
Involvement of Cell Surface Heparan Sulfate in the Density-Dependent Inhibition of Cell Proliferation
}

\author{
Kôzi Matuoka and Youji Mitsui \\ Department of Pharmacology, Tokyo Metropolitan Institute of Gerontology, \\ Sakae-cho 35-2, Itabashi-ku, Tokyo, 173, Japan
}

\begin{abstract}
Growth of human diploid fibroblasts on the cell sheets treated with various fixatives and enzymes was examined in order to investigate the mechanism of the density-dependent inhibition of cell proliferation. Growth was inhibited about $40 \%$ when fibroblasts were cultured on glutaraldehydefixed cell sheets of late passage cells, compared with cell growth on perchloric acid-fixed cell sheets or in control cultures without cell sheets. Treatment of glutaraldehyde-fixed cell sheets with heparitinase or nitrous acid caused the complete loss of the inhibitory effect. When fibroblasts were cultured on glutaraldehyde-fixed cell sheets derived from early, middle and late passage cell cultures, cell growth on the late passage cell sheets showed greater inhibition. These inhibitory effects of the cell sheets correlated well with both the relative amount of heparan sulfate to the total glycosaminoglycans in the cell layer and to the saturation density at each passage. These findings indicate that heparan sulfate (or its complex) on the cell surface is involved in the density-dependent inhibition of cell proliferation.
\end{abstract}

When normal cells, including human diploid fibroblasts, became crowded in culture, they exhibited density-dependent or contact inhibition of cell proliferation. Tumor cells and virally or chemically transformed cells showed little inhibition of growth; even in crowded cultures they formed multilayers by piling up (20). In examinations of density-dependent inhibition, malignant cells have been compared with normal cells, and alterations in cell surface characteristics, such as carbohydratecontaining substances $(2,5)$, lectin receptors (3) and sugar uptake $(8)$, have been correlated to the differences between behaviour of normal and malignant cells at cell contact. The mechanism of the density-dependent inhibition of cell proliferation, however, is not well understood. The factors controlling density-dependent inhibition have been classified roughly into depletion of growth factors or nutrients $(9,19)$, accumulation of diffusible inhibitory substances in the medium (9) and direct contact interactions $(4,21)$.

We found that the heparan sulfate on the cell surface becomes enriched in late passage human diploid fibroblasts which parallels the decrease in saturation density (cell density at confluency) (unpublished data). Therefore, we investigated the role of cell surface heparan sulfate in direct contact interactions in the density-dependent inhibition of cell proliferation, with a new experimental system in which cells are

Abbreviations: FBS, fetal bovine serum; PBS(-), $\mathrm{Ca}^{2+}, \mathrm{Mg}^{2+}$-free phosphate buffered saline; GA, glutaraldehyde; PCA, perchloric acid; PDL, population doubling level. 
cultivated on fixed cell sheets treated with various enzymatic and chemical degradations. The results indicate that cell surface heparan sulfate is involved in the densitydependent inhibition of cell proliferation.

\section{MATERIALS AND METHODS}

Cell and culture. Human embryo lung fibroblasts, TIG-1, established at the Tokyo Metropolitan Institute of Gerontology (13), were used. The cells were cultured in Eagle's minimum essential medium containing non-essential amino acids (No. 410-1500, Gibco.) supplemented with $10 \%$ fetal bovine serum (FBS) (No. 200-6140, Gibco.), L-glutamine $(2 \mathrm{mM})$, potassium penicillin $\mathrm{G}(100 \mathrm{units} / \mathrm{ml})$ and streptomycin sulfate $(100 \mu \mathrm{g} / \mathrm{ml})$ in an environment of $5 \% \mathrm{CO}_{2}$ and $95 \%$ air at $37^{\circ} \mathrm{C}$. Routine subculture was performed by harvesting cells with $0.25 \%$ trypsin $\left(1: 250\right.$, Difco.) solution in $\mathrm{Ca}^{2+}, \mathrm{Mg}^{2+}$-free phosphate buffered saline, pH 7.4 (PBS(-)). The volumes of the medium and solutions used were 2,5 and $10 \mathrm{ml}$ for the cell cultures in $30 \mathrm{~mm}, 60 \mathrm{~mm}$ and $90 \mathrm{~mm}$ diameter plastic dishes (Falcon.), unless otherwise stated. Mycoplasmal contamination was tested by the uridine/uracil method (12).

Preparation of the fixed cell sheets. Cells cultured to confluency were washed twice with PBS(-), then fixed with $2.5 \%$ glutaraldehyde (GA) (Oken Shoji, Tokyo) at room temperature for $30 \mathrm{~min}$ and washed 3 times with PBS(-). The fixed cell sheets were incubated in FBS-free medium at room temperature for $1 \mathrm{~h}$, then washed twice with PBS( - ). Some cell sheets were treated with enzymes or nitrous acid as described later. The treated or untreated cell sheets were washed with $1 \%$ perchloric acid (PCA) for $10 \mathrm{~min}$ on ice and 3 times with distilled water on ice. Several control cell sheets were prepared with parallel cultures by fixing them with $1 \%$ PCA, AcOH or EtOH for 30 min on ice or by further treatment with $2.5 \%$ GA and $1 \%$ PCA. All the cell sheets were washed with distilled water and incubated in FBS-free medium overnight at $37^{\circ} \mathrm{C}$ before use for cultivation. These procedures were carried out under sterile conditions. We prepared several kinds of cell sheets: No. 1 GAfixed/PCA-washed cell sheets, No. 2 GA-fixed/enzyme- or nitrous acid-treated/PCA-washed cell sheets, No. 3 PCA-fixed cell sheets, No. 4 PCA-fixed/GA-treated/PCA-washed cell sheets, No. $5 \mathrm{AcOH}$-fixed cell sheets and No. 6 EtOH-fixed cell sheets.

Cell culture on the fixed cell sheets. Fibroblasts were harvested from confluent cultures by trypinization, then inoculated into dishes with the fixed cell sheets at a concentration of 3-6 $\times 10^{3} \mathrm{~cm}^{-2}$ after which they were cultured under standard conditions. At various intervals, cells were harvested by treatment for $30 \mathrm{~min}$ at room temperature with $0.125 \%$ trypsin in PBS $(-)$ containing $0.005 \%$ neutral red. The number of neutral red-stained viable cells was counted with a hemacytometer.

Enzymatic and nitrous acid treatment of the fixed cell sheets. Glycosaminoglycans on the cell sheets were degraded under the following conditions: No. 1 Streptomyces hyaluronidase (Seikagaku Kogyo, Tokyo) (0.03 TRU per $\mathrm{cm}^{2}$ ) in $0.05 \mathrm{M}$ acetate buffer, pH 5.0 for $4 \mathrm{~h}$ at $50^{\circ} \mathrm{C}(15)$; No. 2 chondroitinase $\mathrm{ABC}$ (Seikagaku Kogyo, Tokyo) $\left(0.0015\right.$ units per $\mathrm{cm}^{2}$ ) in $0.13 \mathrm{M}$ Tris- $\mathrm{HCl}$, pH 8.0, containing $0.1 \mathrm{M} \mathrm{NaOAc}, 0.12 \mathrm{M} \mathrm{NaCl}$ and $0.25 \mathrm{mg} / \mathrm{ml}$ of bovine serum albumin for $4 \mathrm{~h}$ at $37^{\circ} \mathrm{C} \mathrm{(22)}$; No. 3 nitrous acid $(0.2 \mathrm{ml}$ of the solution per $\left.\mathrm{cm}^{2}\right)$ as a mixture of $18 \% \mathrm{w} / \mathrm{w} \mathrm{NaNO}_{2}$ aqueous solution, $\mathrm{AcOH}$ and $\mathrm{H}_{2} \mathrm{O}(1: 1: 8, \mathrm{v} / \mathrm{v} / \mathrm{v})$ for $80 \mathrm{~min}$ at room temperature (7) and No. 4 Flavobacterium heparitinase (87 units/mg), which was the gift of Professor I. Yamashina, Kyoto University, $\left(1.1 \mu \mathrm{g}\right.$ per $\left.\mathrm{cm}^{2}\right)$ for $4 \mathrm{~h}$ or indicated intervals at $43^{\circ} \mathrm{C}$.

Isolation and determination of glycosaminoglycans from the fixed cell sheets. The cells in confluent cultures were incubated with [ $\left.{ }^{3} \mathrm{H}\right] \mathrm{D}$-glucosamine $\mathrm{HCl}(38 \mathrm{Ci} / \mathrm{mmol}$, Radiochemi- 
cal Centre, Amersham) or [ ${ }^{35} \mathrm{~S}_{3} \mathrm{H}_{2} \mathrm{SO}_{4}$ (carrier free, Japan Atomic Energy Research Institute, Tokyo) for $48 \mathrm{~h}$ under standard culture conditions (Concentrations of radioisotopes are given in the legends.). The cell layers were washed 3 times with PBS(-) then fixed with GA as described above. The cell sheets, treated or untreated with the enzymes or nitrous acid, were scraped with a Teflon sheet in $0.5 \mathrm{~N} \mathrm{NaOH}$ solution. The glycosaminoglycans were isolated by pronase digestion and cetyl pyridinium chloride precipitation according to Otsuka et al. (16)) and analyzed by two-dimensional electrophoresis (6).

Determination of glycosaminoglycans and heparan sulfate contents in the cell layers. Confluent cultures in 4 dishes $(90 \mathrm{~mm})$ were used for each determination of the uronic acid and heparan sulfate contents. Glycosaminoglycans in the cell layers were isolated from the whole cells as described previously (16). The heparan sulfate content was measured by the indole$\mathrm{HCl}$ method (11), with heparan sulfate from bovine kidney (Seikagaku Kogyo, Tokyo) as the standard; The uronic acid content was measured by the carbazole $-\mathrm{H}_{2} \mathrm{SO}_{4}$ method (1).

\section{RESULTS}

Effect of fixed cell sheets on cell growth. Growth of fibroblasts cultured on fixed cell sheets was examined (Fig. 1). When cells were cultured on GA-fixed cell sheets prepared from late passage cells (population doubling level (PDL) 53), the increase in cell number was inhibited by $27 \%$ in the growing phase and by $42-47 \%$ at confluency. This decrease in cell number was not due to a decrease in cell attachment on the GA-fixed cell sheets, because the cell number on the cell sheets at the 23rd hour after inoculation was $17 \%$ higher than that in control cultures without cell sheets. In contrast, PCA-fixed cell sheets produced slight stimulation of cell growth (Fig. 1)

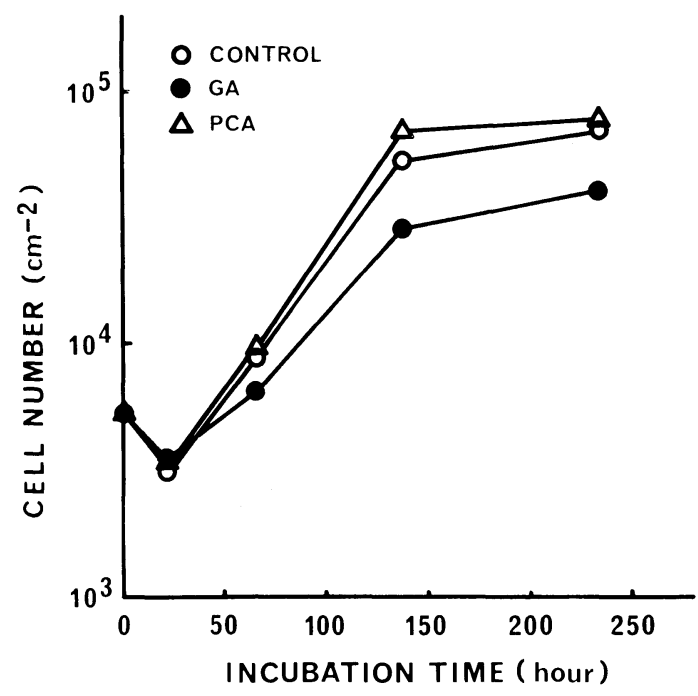

Fig. 1. Effect of GA- and PCA-fixed cell sheets on cell growth. The cells at PDL 53 were inoculated at a concentration of $5.2 \times 10^{3} \mathrm{~cm}^{-2}$ onto plastic substrates in $30 \mathrm{~mm}$ dishes without cell sheets (open circle), with GA-fixed cell sheets (closed circle) or PCA-fixed cell sheets (triangle). Fixed cell sheets were prepared from confluent cultures of cells at PDL 52. Each point represents the mean of three dishes. 


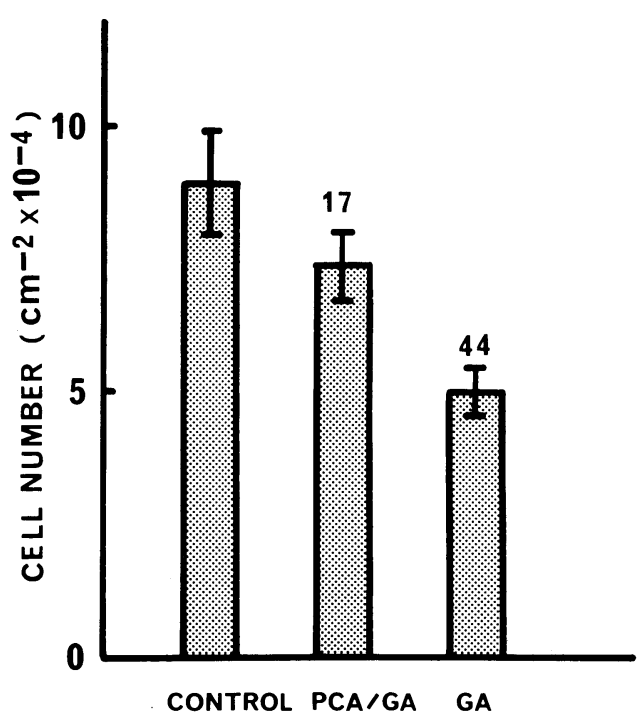

Fig. 2. Effect of preparation procedures for cell sheets on cell growth. Cells at PDL 49 were inoculated at a concentration of $3.47 \times 10^{3} \mathrm{~cm}^{-2}$ onto plastic substrates in $30 \mathrm{~mm}$ dishes without cell sheets (control), with PCA-fixed/GA-treated cell sheets (PCA/GA) or GA-fixed cell sheets (GA). Cell sheets were prepared from confluent cultures of cells at PDL 47. Cell numbers were counted $167 \mathrm{~h}$ after inoculation. Each bar represents the mean \pm standard error of three counts. Each figure on the bar shows the percent of inhibition of the control.

(as did cell sheets fixed with $\mathrm{AcOH}(+16 \%)$ or $\mathrm{EtOH}(+28 \%)$ ). The observed difference between GA and PCA in the effect of fixed cell sheets on cell growth might be due to differences in structural alterations on the cell surface caused by each fixative.

The contribution of the cytotoxic effect of GA fixation was checked by treatment of the PCA-fixed cell sheets with GA. The PCA-fixed/GA-treated cell sheets inhibited cell growth only by $17 \%$, whereas the GA-fixed cell sheets inhibited it by $44 \%$ (Fig. 2 ). The cytotoxic effect of GA treatment on cell growth is, if at all, one third of the growth inhibiting effect of the GA-fixed cell sheets. These findings show that the GA-fixed cell sheets may have some characteristics that are involved in the densitydependent inhibition of cell proliferation.

Degradation of glycosaminoglycans on GA-fixed cell sheets. The involvement of glycosaminoglycans in the inhibitory effect on cell growth of GA-fixed cell sheets was examined by the enzymatic and chemical degradations of radioisotope-labeled cell sheets. Hyaluronidase, chondroitinase $\mathrm{ABC}$ and nitrous acid specifically degraded hyaluronate, chondroitin sulfates (including dermatan sulfate) and heparan sulfate, although GA fixation removed $20-33 \%$ of the glucosaminoglycans in the cell layer but not specifically to a particular glycosaminoglycan (Table 1). The degradation of heparan sulfate with nitrous acid was almost total, whereas each enzyme degraded $75-78 \%$ of the corresponding substrate in the cell layer. Similar results were obtained when cell sheets were treated with heparitinase (Table 2 ). $75 \%$ of the total radioactivity in heparan sulfate was released by heparitinase treatment, but $106 \%$ by nitrous acid treatment. This may not mean incomplete enzymatic degradation, but maximal 


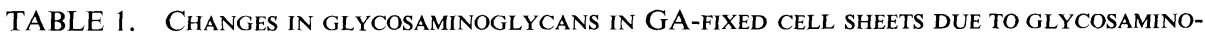
GLYCAN-DEGRADING TREATMENTS

\begin{tabular}{|c|c|c|c|}
\hline & \multicolumn{3}{|c|}{ Radioactivity (dpm/dish) } \\
\hline & Hyaluronate & Chondroitin sulfates $^{\mathrm{a}}$ & Heparan sulfate \\
\hline Whole cell layers & 12,860 & 5,660 & 9,350 \\
\hline \multicolumn{4}{|l|}{ GA-fixed cell sheets } \\
\hline Untreated & $9,780(-24 \% \mathrm{~b})$ & $4,540(-20 \% \mathrm{~b})$ & $6,270(-33 \%$ b $)$ \\
\hline Hyaluronidase-treated & $2,450(-75 \% \mathrm{c})$ & $4,870\left(+7 \%^{c}\right)$ & $5,900\left(-6 \%{ }^{c}\right)$ \\
\hline Chondroitinase $\mathrm{ABC}$-treated & $9,460\left(-3 \%^{c}\right)$ & $1,010\left(-78 \%^{\mathrm{c}}\right)$ & $6,3220\left(+1 \%^{c}\right)$ \\
\hline Nitrous acid-treated & $8,480\left(-13 \%^{c}\right)$ & $4,950\left(+9 \%^{c}\right)$ & $760\left(-88 \%{ }^{c}\right)$ \\
\hline
\end{tabular}

a includes dermatan sulfate

b $\%$ change in whole cell layers

c $\%$ change in untreated cell sheets

Cells at PDL 46 in confluent cultures $\left(60 \mathrm{~mm}\right.$ dish) were incubated with $\left[{ }^{3} \mathrm{H}\right]$ glucosamine $(5 \mu \mathrm{Ci} /-$ $\mathrm{ml} \times 5 \mathrm{ml} / \mathrm{dish}$ ) for $48 \mathrm{~h}$ and fixed with GA. Cell sheets were treated with the enzymes and nitrous acid as in MATERIALS AND METHODS. Residual glycosaminoglycans were isolated and analyzed by twodimensional electrophoresis. Each value is the mean of two dishes.

TABLE 2. DEgradation OF HEPARAN SUlfate in GA-FIXED CELl SHEETS WITH HEPARITINASE AND NITROUS ACID

\begin{tabular}{lcc}
\hline & \multicolumn{2}{c}{ Radioactivity $(\mathrm{dpm})$} \\
\cline { 2 - 3 } & Bound to cells & Released from cells \\
\hline Untreated cell sheets & $1,044,000\left(382,000^{\mathrm{a}}\right)$ & \\
Heparitinase-treated & 786,000 & $287,000\left(75 \% \mathrm{o}^{\mathrm{b}}\right)$ \\
Nitrous acid-treated & 604,000 & $405,000\left(106 \% \mathrm{~b}^{\mathrm{b}}\right)$ \\
\hline
\end{tabular}

a heparan sulfate in untreated cell sheets

b $\%$ of heparan sulfate in untreated cell sheets (a)

Cells at PDL 52 in confluent cultures ( $90 \mathrm{~mm}$ dish) were incubated with $\left[{ }^{3} \mathrm{H}\right]$ glucosamine $(4 \mu \mathrm{Ci} / \mathrm{ml} \times$ $10 \mathrm{ml} / \mathrm{dish}$ ) for $48 \mathrm{~h}$ and fixed with GA. Cell sheets were treated with heparitinase or nitrous acid as in MATERIALS AND METHODS. Residual and released radioactivities were measured. Heparan sulfate in untreated cell sheets was assayed by electrophoretic analysis.

digestion because the time course experiment for heparitinase digestion of GA-fixed cell sheets labeled with $\left[{ }^{3} \mathrm{H}\right]$ glucosamine and $\left[{ }^{35} \mathrm{~S}_{3} \mathrm{H}_{2} \mathrm{SO}_{4}\right.$ shows that digestion was completed in $3 \mathrm{~h}$ (Fig. 3). Therefore, about $25 \%$ of the glycosaminoglycans in the sheets were kept from the enzymatic digestion by their positions. Protease activity in the heparitinase preparation was negligible in the results of an experiment on GA-fixed cell sheets that had been labeled with ${ }^{3} \mathrm{H}$-amino acid mixture. (Only $0.3 \%$ of the total radioactivity incorporated into the cellular proteins was released by heparitinase treatment.)

Effect of the glycosaminoglycan-degraded cell sheets on cell growth. Chondroitinase ABC treatment of the GA-fixed cell sheets caused no changes in the growth-inhibiting effect. Hyaluronidase treatment produced slight recovery, whereas greater cell density was regained by treatment with heparitinase up to the level of the PCA-fixation/GAtreatment. Similar results were obtained with nitrous acid-treated cell sheets (Fig. 5). 
When the GA-fixed cell sheets were treated with nitrous acid, they retained only a part of their growth-inhibiting ability.

Relationship between the growth-inhibition effect of GA-fixed cell sheets and the relative amount of heparan sulfate in early, middle and late passage cells. We examined

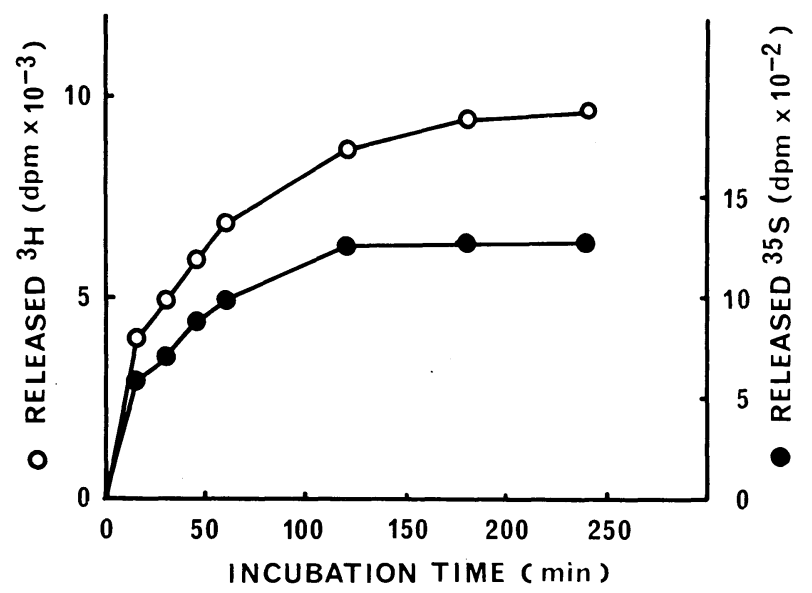

Fig. 3. Time course of heparitinase treatment. Cells at PDL 57 in confluent cultures were incubated with [ $\left.{ }^{3} \mathrm{H}\right]$ glucosamine $(2.25 \mu \mathrm{Ci} / \mathrm{ml} \times 5 \mathrm{ml} / \mathrm{dish})$ and $\left[{ }^{35} \mathrm{~S}^{3} \mathrm{H}_{2} \mathrm{SO}_{4}(5.0 \mu \mathrm{Ci} / \mathrm{ml} \times 5 \mathrm{ml} / \mathrm{dish})\right.$ for $48 \mathrm{~h}$. The cell layers were fixed with GA then digested with heparitinase ( $22 \mu \mathrm{g} / 60 \mathrm{~mm}$ dish) for the indicated periods at $43^{\circ} \mathrm{C}$ as described in MATERIALS AND METHODS. The released radioactivities of ${ }^{3} \mathrm{H}$ (open circle) and ${ }^{35} \mathrm{~S}$ (closed circle) were measured.

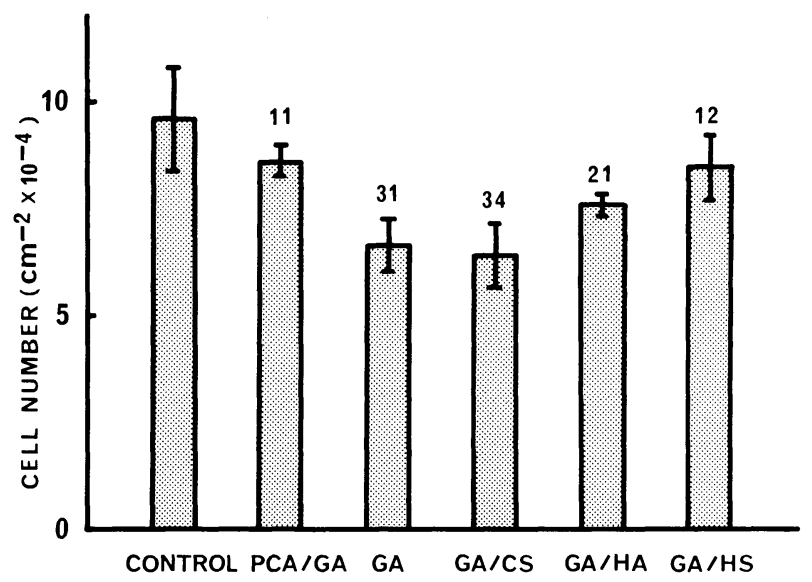

Fig. 4. Growth-inhibiting effect of GA-fixed cell sheets after glycosaminoglycan-degrading treatments. Cells at PDL 49 were inoculated at a concentration of $3.5 \times 10^{3} \mathrm{~cm}^{-2}$ onto plastic substrates in $30 \mathrm{~mm}$ dishes without cell sheets (control) or with PCA-fixed/GA-treated (PCA/GA), GA-fixed (GA), GA-fixed/chondroitinase ABC-treated (GA/CS), GA-fixed/hyaluronidase-treated (GA/HA) or GA-fixed/heparitinase-treated cell sheets $(\mathrm{GA} / \mathrm{HS})$ prepared from cells at PDL 47. Cell numbers were counted $286 \mathrm{~h}$ after inoculation. Each bar represents the mean \pm standard error of four counts. Each figure on the bar shows the percent of the inhibition of the control. 


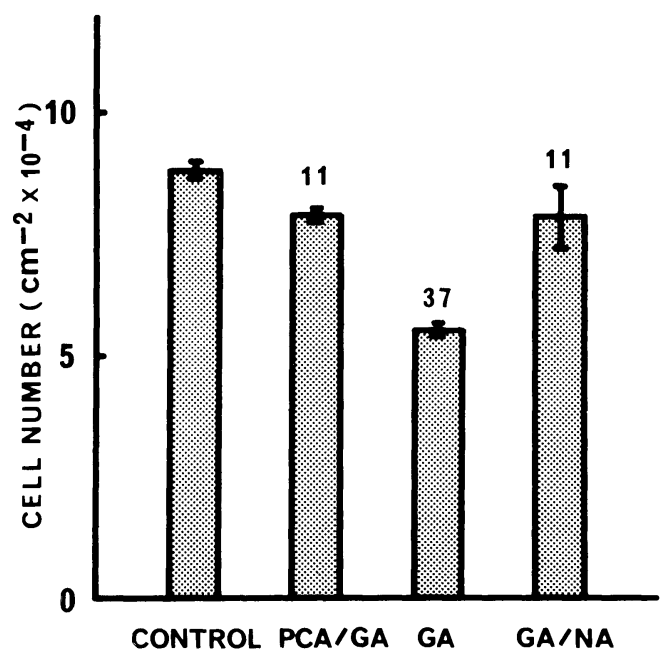

Fig. 5. Growth-inhibiting effect of GA-fixed cell sheets after nitrous acid treatment. Cells at PDL 56 were inoculated at a concentration of $5.0 \times 10^{3} \mathrm{~cm}^{-2}$ onto plastic substrates in $30 \mathrm{~mm}$ dishes without cell sheets (control) or with PCA-fixed/GA-treated (PCA/GA), GA-fixed (GA) or GA-fixed/nitrous acid-treated cell sheets (GA/NA) prepaerd from cells at PDL 54.5. Cell numbers were counted $142 \mathrm{~h}$ after inoculation. Each bar represents the mean \pm standard error of four counts. Each figure on the bar shows the percent of inhibition of the control.

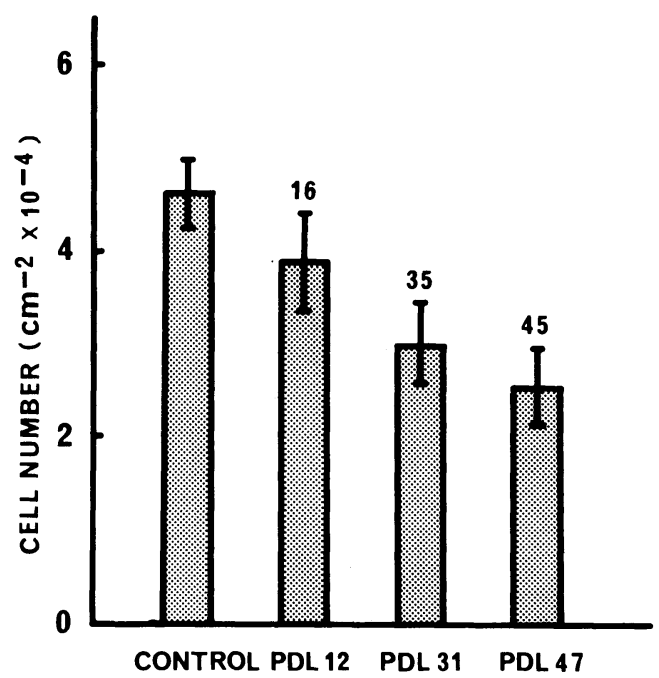

Fig. 6. Effect of early, middle and late passage cell sheets on cell growth. Cells at PDL 49 were inoculated at a concentration of $5.0 \times 10^{3} \mathrm{~cm}^{-2}$ onto plastic substrates in $30 \mathrm{~mm}$ dishes without cell sheets (control) or with GA-fixed cell sheets of early (PDL 12), middle (PDL 31) or late passage cells (PDL 47). Cell numbers were counted $142 \mathrm{~h}$ after inoculation. Each bar represents the mean \pm standard error of four counts. Each figure on the bar shows the percent of inhibition of the control. 
the growth of fibroblasts on GA-fixed cell sheets prepared from early, middle and late passage cells. Early passage cell sheets inhibited cell growth by $16 \%$, middle and late passage cell sheets by $35 \%$ and $45 \%$, when compared with control cultures without cell sheets. The degree of the growth-inhibiting effect of the GA-fixed cell sheets should be correlated with amount of heparan sulfate on each cell sheet, because we found an increase in cell surface heparan sulfate during in vitro aging.

The determination of the heparan sulfate and total glycosaminoglycan contents
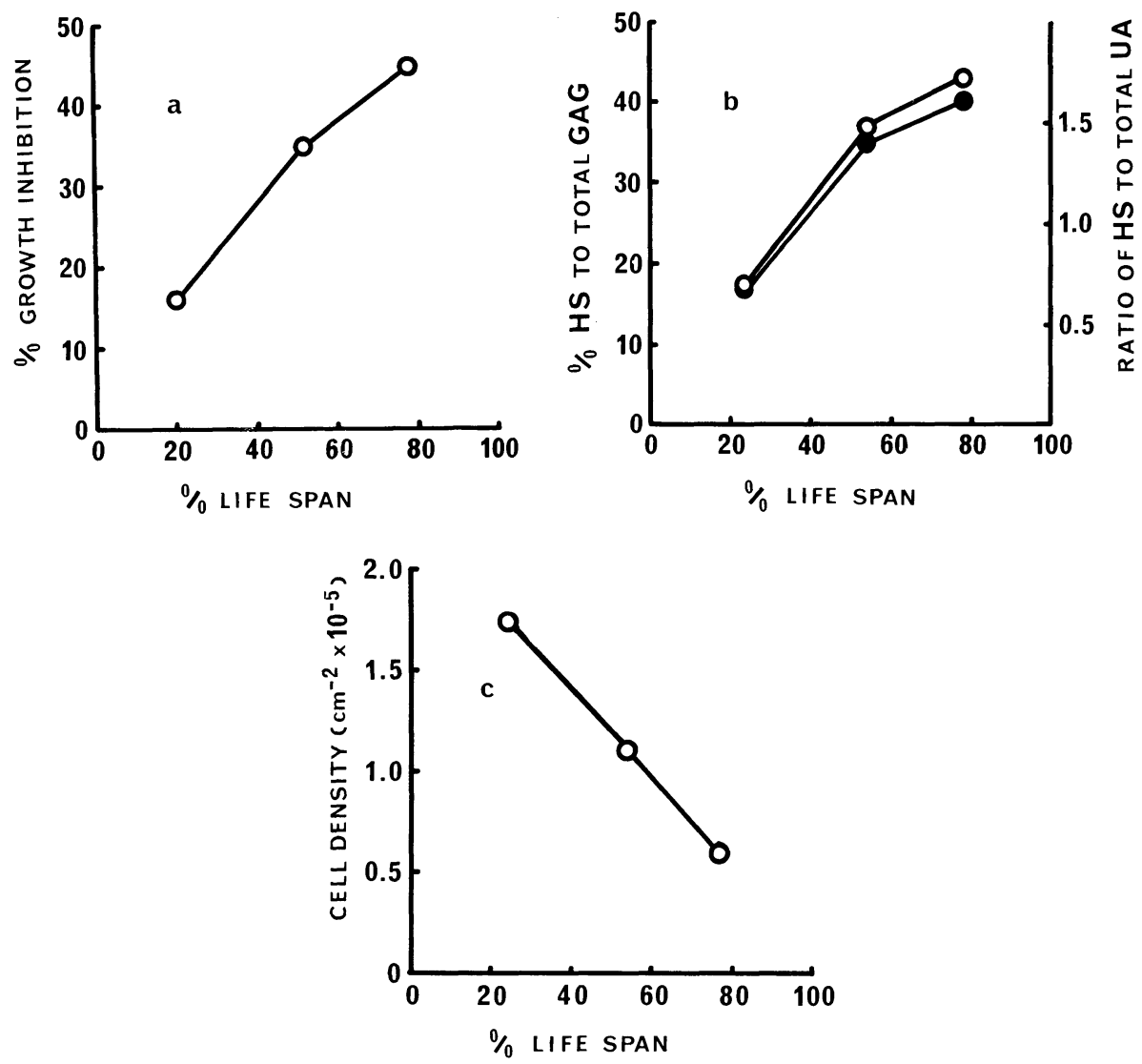

Fig. 7. (a) Change in the growth-inhibiting effects of GA-fixed cell sheets with in vitro age. The effects of cell sheets on cell growth, given Fig. 6, were plotted against the percentage life span of the fixed cells (life span: PDL 60). (b) Change in the relative amount of heparan sulfate to the total glycosaminoglycans in the cell layer with in vitro age. Cells at PDL 19, 43 and 63 were inoculated in the split ratio of $1: 5$ into $90 \mathrm{~mm}$ dishes. Nine days after inoculation the glycosaminoglycans in the cell layers were isolated for the assays of the heparan sulfate and total uronic acid contents as in Materials AND methods. Parallel cultures were incubated with $\left[{ }^{3} \mathrm{H}\right]$ glucosamine $(5 \mu \mathrm{Ci} / \mathrm{ml} \times 10$ $\mathrm{ml} /$ dish) for $48 \mathrm{~h}$, on the 7 th day after inoculation. Labeled glycosaminoglycans were analyzed as in MATERIALS AND METHODS. The relative amount of heparan sulfate to the total glycosaminoglycans (net amount: open circle; newly synthesized: closed circle) was plotted against the percentage life span (life span: PDL 79). (c) Change in saturation density with in vitro age. Cells at PDL 19, 43 and 63 were inoculated in the split ratio of $1: 5$ into $90 \mathrm{~mm}$ dishes. Cell numbers were counted 9 days after inoculation. 
TABLE 3. ChANGES IN SUSCEPTIBILITY to GA-FIXED CELl SHEETS WITH in vitro AGE

\begin{tabular}{ccc}
\hline & \multicolumn{3}{c}{ Cell number $\left(\mathrm{cm}^{-2} \times 10^{-4}\right)$} \\
\cline { 2 - 3 } & On plastic substrates & On GA-fixed cell sheets \\
\hline PDL 18 & $254 \pm 7$ & $172 \pm 6 \quad\left(3 \%^{\mathrm{a}}\right)$ \\
PDL 48 & $105 \pm 2$ & $70 \pm 1 \quad\left(33 \%^{\mathrm{a}}\right)$ \\
PDL 59 & $13.6 \pm 0.0$ & $8.4 \pm 0.1\left(39 \%{ }^{\mathrm{a}}\right)$ \\
\hline
\end{tabular}

a $\%$ inhibition of the control (plastic substrates)

Cells at PDL 18, 48 and 59 were inoculated at a concentration of $5 \times 10^{3} \mathrm{~cm}^{-2}$ onto plastic substrates without cell sheets (control) or onto GA-fixed cell sheets of late passage cells (PDL 55), then cultured under standard conditions. Cell numbers were counted $170 \mathrm{~h}$ after inoculation. Each value is the mean \pm standard error of four dishes.

in the cell layer showed that the relative amount of heparan sulfate when compared to the total glycosaminoglycans increased 2.4 times, from PDL 19 to PDL 63 (Fig. $7 \mathrm{~b})$. Identical results were obtained with newly synthesized glycosaminoglycans in the cell layer on examination of radioactive precursor incorporation (Fig. 7b). The relative amount of heparan sulfate as compared to the total glycosaminoglycans increased from $17 \%$ at PDL 19 to $43 \%$ at PDL 63 (2.5 times). These changes, which were correlated inversely with the saturation density, decreased linearly with in vitro age (Fig. 7c).

When the growth-inhibiting effects of the GA-fixed cell sheets were plotted against the percentage life span (percentage of in vitro age (PDL) to in vitro life span (PDL)) (Fig. 7a), the changes were in good agreement with the relative amount of heparan sulfate and the saturation density at each passage. Therefore, the relative amount of heparan sulfate on the cell surface might be important in the density-dependent inhibition of cell proliferation.

Change in cellular susceptibility to the fixed cell sheets during in vitro aging. The above results indicate that the lower saturation density of the late passage cells (18) might be due to reciprocal inhibition of cell proliferation at contact with the heparan sulfate-enriched cell surface in late passage cell cultures. There remains, however, the possibility that there is greater susceptibility to cell contact in late passage cells. Thus, we examined the inhibitory effects of GA-fixed cell sheets on the growth of early, middle and late passage cells (Table 3 ). The growth in early, middle and late passage cells was inhibited to a similar extent, $32 \%, 33 \%$ and $39 \%$, which eliminates the possibility of age-related changes in the susceptibility to cell contact.

\section{DISCUSSION}

To investigate what characteristics are involved in the density-dependent inhibition of cell proliferation, we originated a method, cell cultivation on fixed cell sheets. Compared with the use of feeder layers of non-proliferating living cells, our method had that advantage that the observed effects were free from any function of feeder cells, and were attributed to the surface structure of the fixed cells.

The cultivation of cells on GA-fixed cell sheets resulted in growth inhibition, but cells fixed with PCA (as with $\mathrm{AcOH}$ and $\mathrm{EtOH}$ ) showed no inhibition of cell growth. GA treatment may cause fixation of the cell surface structure with minimal alterations 
in the original conformation, in contrast with non-specific denaturation of proteins caused by $\mathrm{PCA}, \mathrm{AcOH}$ and $\mathrm{EtOH}$ treatments. Thus, growing cells might recognize GA-fixed cells as an acting cell surface structure and cease to proliferate due to the density-dependent inhibition of cell proliferation.

The growth-inhibiting effect of the GA-fixed cell sheets was lost after heparan sulfate-degrading treatments (heparitinase and nitrous acid). This is evidence that the effect of the fixed cells in contact with living cells is probably due to the cell surface heparan sulfate. An addition of a high concentration of heparan sulfate to the culture medium has been reported to cause inhibition of the growth of human diploid fibroblasts (17), and rat hepatoma cells have recovered the density-dependent inhibition of cell proliferation on the addition of glycosaminoglycans (considered heparan sulfate) isolated from the surface of normal liver cells (14). Our findings are consistent with these reports.

The saturation density of human diploid fibroblasts decreased progressively during in vitro aging (18) and the cell surface of late passage human diploid fibroblasts was enriched with heparan sulfate (unpublished data). This decrease in saturation density might result from increased amounts of heparan sulfate on late passage cell surfaces. Our experiments with fixed cells at early, middle and late passages demonstrated that the late passage cell sheets produced greater inhibition of growth, which correlated with the relative amount of heparan sulfate to the total glycosaminoglycans in the cell layers and to the saturation density. Furthermore, the susceptibility of early, middle and late passage cells to the GA-fixed cells was the same.

Thus, we consider that the density-dependent inhibition of cell proliferation in human diploid fibroblasts is regulated, at least partly, by cell surface heparan sulfate (or its complex) and that the decline in the saturation density during aging is subordinate to changes in the heparan sulfate on the cell surface. These findings offer an important clue to the density-dependent inhibition of cell proliferation and cellular aging.

Acknowledgements. We thank Professor Ikuo Yamashina, Kyoto University, for the generous gift of purified heparitinase. This investigation was supported in part by a Grant-in-Aid for Scientific Research from the Ministery of Education, Science and Culture.

\section{REFERENCES}

1. Bitter, T. and H.M. Muir. A modified uronic acid carbazole reaction. Anal. Biochem. 4, 330334, 1962

2. BUCK, C.A., M.C. GLICK and L. WARREN. Glycopeptide from the surface of control and virustransformed cells. Science 172, 169-171, 1971

3. Burger, M.M.. Proteolytic enzymes initiating cell division and escape from contact inhibition of growth. Nature 227, 170-171, 1970

4. Dulbecco, R. and M.G.P. Stoker. Conditions determining initiation of DNA synthesis in 3T3 cells. Proc. Natl. Acad. Sci. U. S. A. 66, 204-210, 1970

5. HAKomori, S., T. SAITO and P.K. VoGT. Transformation by Rous sarcoma virus: effects on cellular glycolipids. Virology 44, 609-621, 1971

6. Hata, R. and Y. NAGAI. A rapid and micro method for separation of acidic glycosaminoglycans by two-dimensional electrophoresis. Anal. Biochem. 45, 462-468, 1972

7. Hata, R. and Y. Nagai. Distribution of acidic glycosaminoglycans in tadpole back skin. Biochim. Biophys. Acta 304, 408-412, 1973

8. Hatanaka, M. and J. Hanafusa. Analysis of a functional change in membrane in the process 
of cell transformation by Rous sarcoma virus: alteration in the characteristics of sugar transport. Virology 41, 647-652, 1970

9. Holley, R.W. and J.A. KIERnan. "Contact inhibition" of cell division in 3 T3 cells. Proc. Natl. Acad. Sci. U.S.A. 60, 300-304, 1968

10. Kozutsumi, Y., N. Iтон, K. Fujimoto, T. Kawasaki and I. Yamashina. Isolation and characterization of mucopolysaccharides from rat liver mitochondria. J. Biochem. 86, 1049-1054, 1979

11. Lagunoff, D. and G. Warren. Determination of 2-deoxy-2-sulfo-aminohexose content of mucopolysaccharides. Arch. Biochem. Biophys. 99, 396-400, 1962

12. McGarrity, G.J., V. Vanaman and J. Sarama. Comparative studies between microbiological culture and uptake of uridine/uracil to detect mycoplasmal infection of cell cultures. Exp. Cell Res. 121, 159-165, 1979

13. Ohashi, M., S. Aizawa, H. Ooka, T. Ohsawa, K. Kaji, H. Kondo, T. Kobayashi, T. Noumura, M. Matsuo, M. Mitsui, S. Murota, K. Yamamoto, H. Ito, H. Shimada and T. UtAkoJi. A new human diploid cell strain, TIG-1, for the research on cellular aging. Exp. Gerontol. 14, 121-133, 1980

14. OhNishi, T., E. OHshima and M. OHtsuka. Effect of liver cell coat acid mucopolysaccharide on the appearance of density dependent inhibition in hepatoma cell growth. Exp. Cell Res. 93, 136-142, 1975

15. OhyA, T. and Y. KAneko. Novel hyaluronidase from streptomyces. Biochim. Biophys. Acta 198, 607-609, 1970

16. Otsuka, K., S. Murota and Y. Mori. Stimulatory effect of bleomycin on the synthesis of acidic glycosaminoglycans in cultured fibroblasts derived from rat carrageenin granuloma. Biochim. Biophys. Acta 444, 359-368, 1976

17. Schachtschabel, D.O., J. Wever, G. Sluke and G. Wever. Influence of exogenous glycosaminoglycans on growth and glycosaminoglycan synthesis of cultured human diploid fibroblasts (WI-38). Z. Gerontol. 12, 19-26, 1979

18. Schneider, E.L. and Y. Mitsui. Temporal sequence of "aging" parameters in cultured human diploid fibroblasts. Proc. 10th Intern. Congr. Gerontol. 1, 140-142, 1975

19. Stoker, M. and D. Piggott. Shaking 3T3 cells: further studies on diffusion boundary effects. Cell 3, 207-215, 1974

20. Stoker, M.G. and H. Rubin. Density dependent inhibition of cell growth in culture. Nature 215, 171-172, 1967

21. Todaro, G.J., H. Green and B.D. GoldberG. Transformation of properties of an established cell line by SV40 and polyoma virus. Proc. Natl. Acad. Sci. U. S. A. 51, 66-73, 1963

22. Yamagata, T., H. Saito, O. Habuchi and S. Suzuki. Purification and properties of bacterial chondroitinases and chondrosulfatases. J. Biol. Chem. 243, 1523-1535, 1968

(Received for publication, January 30, 1981) 